\title{
A Retrospective Application of the European Society for Paediatric Gastroenterology Hepatology and Nutrition Guidelines for Diagnosis of Coeliac Disease in New Zealand Children
}

\author{
Wendy Miller ${ }^{1}$, Andrew S Day ${ }^{2, *}$ \\ ${ }^{1}$ Paediatric Department, Nelson Hospital, Nelson, New Zealand \\ ${ }^{2}$ Paediatric Department, Christchurch Hospital, Christchurch, New Zealand \\ *Corresponding author: andrew.day@otago.ac.nz
}

Received November 03, 2014; Revised November 25, 2014; Accepted December 03, 2014

\begin{abstract}
In 2012 the European Society for Pediatric Gastroenterology, Hepatology, and Nutrition (ESPGHAN) published an updated guideline for the diagnosis of Coeliac disease, allowing symptomatic individuals with appropriate serology and HLA genotype to be diagnosed without a small bowel biopsy. This retrospective study aimed to assess the applicability of this guideline to children in New Zealand. Children less than 16 years of age investigated for coeliac disease with small bowel biopsy in Christchurch Hospital between January 2010 and December 2012 were identified. The results of those with tissue transglutaminase IgA (tTG) levels greater than 50 units (10 times upper limit of normal), positive endomysial antibodies and HLA DQ2/DQ8 were used to calculate sensitivity and specificity. Data from 160 children was available: 70 had biopsy-confirmed Coeliac disease, and 90 had negative biopsies. Limited data precluded application of the guidelines to all patients. Using only tTG data, levels above 50 units provided a sensitivity of $67 \%$ and a specificity of $92 \%$. Specificity increased to $97 \%$ when limited EMA and HLA DQ2/DQ8 data was added. Despite limited data, applying the ESPGHAN guidelines in the Christchurch paediatric population over this period produced a high specificity (97\%). Prospective studies are now required to confirm these findings.
\end{abstract}

Keywords: ESPGHAN, tissue transglutaminase, endomysial antibodies, $H L A-D Q 2 / D Q 8$, children

Cite This Article: Wendy Miller, and Andrew S Day, "A Retrospective Application of the European Society for Paediatric Gastroenterology Hepatology and Nutrition Guidelines for Diagnosis of Coeliac Disease in New Zealand Childre." International Journal of Celiac Disease, vol. 2, no. 4 (2014): 126-130. doi: 10.12691/ijcd-2-4-8.

\section{Introduction}

Coeliac disease $(\mathrm{CD})$ is a systemic immune-mediated disorder triggered by dietary gluten in genetically susceptible individuals. [1] CD may present with a variety of gastrointestinal or extraintestinal symptoms. These may include diarrhoea, constipation, abdominal pain, nausea, vomiting, weight loss, failure to thrive, delayed puberty, iron deficiency anaemia, irritability, and fatigue. [2] Greater appreciation of the wide spectrum of presenting features of $\mathrm{CD}$ has led to increased focus upon this diagnosis. General awareness in the community about CD is also increasing with many restaurants [3] and supermarkets increasing their range of gluten free options. Coincident with this is increased parental awareness of the possibility of CD in their child.

Over recent years, the diagnosis of $\mathrm{CD}$ has been based upon the histological assessment of mucosal biopsies obtained endoscopically from the proximal small bowel. Although this is seen as the gold standard, this investigation is relatively invasive, is not $100 \%$ sensitive, and may lead to some delay in confirmation of the diagnosis. In 2012 the European Society for Paediatric Gastroenterology, Hepatology, and Nutrition (ESPGHAN) reviewed the diagnostic guidelines for $\mathrm{CD}$ and proposed a non-biopsy based diagnostic approach for a proportion of symptomatic children. [2] This guideline proposed that symptomatic children with a highly positive tTG IgA level (at least ten times the upper limit of normal (ULN)), positive endomysial antibodies (on a separate occasion), and an appropriate at risk genotype (HLA DQ2 or DQ8), could be diagnosed with $\mathrm{CD}$ without undergoing a small bowel biopsy (SBB). This new approach excluded specific groups of children, such as asymptomatic children in high risk groups (including those with a first degree relative with CD or those with Type 1 Diabetes mellitus). According to the ESPGHAN guideline, children in these categories should still undergo a traditional assessment with SBB as the defining investigation.

Recent data from New Zealand demonstrates increasing numbers of diagnoses of $\mathrm{CD}$ in children, [4] with one report indicating a prevalence of doctor-diagnosed $\mathrm{CD}$ in $1 \%$ of a group of young children. [5] To date the 
ESPGHAN guidelines have not been utilised in the NZ setting. This study aimed to retrospectively apply the ESPGHAN diagnostic criteria to a group of children assessed in Christchurch, NZ.

\section{Methods}

\subsection{Study Populations}

The study population was children aged less than 16 years who had undergone endoscopic SBB for investigation of possible CD at Christchurch Hospital, Christchurch, NZ, in the three years between 2010 and 2012. The Anatomical Pathology Department Database was used to identify a group of subjects with SBB proven $\mathrm{CD}$ and a control group with normal SBB histology.

\subsection{Data Collection}

The clinical records for each subject were reviewed for information on demographic data (including age, ethnicity, and gender), growth parameters, symptoms, personal history, family history, and relevant investigations. Demographic data was obtained from the Hospital database. Growth concerns were recorded if mentioned in documentation, a child had lost weight, or had static weight recorded. Information was obtained from General Practitioner referral letters, outpatient and inpatient consultations, endoscopy reports, histology forms, electronic laboratory records, and the Anatomical Pathology Department Database.

\subsection{Laboratory Data}

Tissue transglutaminase $\operatorname{IgA}$ antibody levels were measured by Celikey IgA Varelisa enzyme-linked immunosorbant assay (Phadia AB, Uppsala, Sweden). The normal range for this assay was $<2$ units, equivocal 35units and elevated $>5$ units. Endomysial antibody levels were measured with the NOVA Lite immunofluorescence assay containing primate eosophagus and Monkey Absorbed IgA antibody (Inova Diagnostics, California, USA). This was reported as 'not detected', 'weak' or 'positive'. HLA DQ2 and DQ8 genotypes were measured by sequence specific polymerase chain reaction and reported as 'not detected' or 'positive for HLA-DQ2 and/or DQ8'. The diagnosis of CD was based upon formal histological assessment of the SBB by an Anatomical Pathologist, using features of the Marsh criteria.[6] The control group did not have histological features of CD. The normal ranges of other investigations (iron, ferritin, B12, folate and vitamin D) were as performed by Canterbury Health Laboratories (Christchurch, NZ).

\subsection{Data Analysis}

Statistical comparisons were done with Graphpad QuickCalcs software (GraphPad Software, Inc. La Jolla, CA, USA). [7] The categorical data were compared between groups using contingency table analysis with the $\chi^{2}$ test or the Fisher's exact test, as appropriate. Continuous data were analysed using an unpaired t test. Weight and height $\mathrm{z}$ scores were calculated from growth data with the World Health Organisation percentile calculators and charts. [8,9] A p value of $<0.05$ was considered significant.

\section{Results}

\subsection{Study Population}

Over the three year period from 2010-2012, 194 endoscopic SBB were performed on children under 16 years of age at Christchurch Hospital looking for a diagnosis of CD:34 of these children were excluded from analysis (Table 1). The remaining study population comprised 160 children; 70 with biopsy proven $\mathrm{CD}$, and 90 with biopsies negative for celiac disease.

Table 1. Subjects under 16 years of age who had small bowel biopsies for investigation of coeliac disease were excluded

\begin{tabular}{lc} 
biopsies for investigation of coeliac disease were excluded & Number \\
\hline Description & 11 \\
\hline Follow up biopsies for CD & 9 \\
Inflammatory bowel disease & 6 \\
Investigation for other pathologies & \\
\hline Asymptomatic screening biopsies & 4 \\
Type 1 Diabetics & 3 \\
Children with Down Syndrome & 1 \\
Children with Turners Syndrome & 34 \\
\hline Total &
\end{tabular}

\subsection{Demographics}

There was a higher ratio of females to males among the subjects with CD (1.9:1 versus 1.27:1 in those without; $\mathrm{p}=0.003$ ). (Table 2). There were no differences between the two groups with regards to anthropometry, age, or ethnicity.

Table 2. Demographic characteristics of the study population

\begin{tabular}{lccc}
\hline Demographic Data & Coeliacs & Controls & P value \\
\hline Female & $46(66 \%)$ & $40(44 \%)$ & 0.003 \\
Mean age \pm SD & $7 \mathrm{y} \pm 3 \mathrm{y} 11 \mathrm{~m}$ & $7 \mathrm{y} 5 \mathrm{~m} \pm 4 \mathrm{y} 3 \mathrm{~m}$ & 0.56 \\
Weight $(\mathrm{kg})$ mean Z & $0.14 \pm 1.36$ & $0.22 \pm 1.43$ & 0.75 \\
score \pm SD & $0.14 \pm 1.05$ & $0.21 \pm 1.42$ & 0.82 \\
Height $(\mathrm{cm})$ mean Z & & & \\
score \pm SD & & $78(87 \%)$ & 1.0 \\
Ethnicity & $61(87 \%)$ & $5(5.5 \%)$ & \\
NZ European & $6(8.5 \%)$ & 0 & \\
Other European & $1(1.4 \%)$ & $4(4.4 \%)$ & \\
Other & $1(1.4 \%)$ & 0 & \\
Maori & $1(1.4 \%)$ & $1(1 \%)$ & \\
Tongan & 0 & $1(1 \%)$ & \\
Chinese & 0 & $1(1 \%)$ & \\
Fijian & 0 & & \\
Not Specified & & & \\
\hline
\end{tabular}

\subsection{Symptoms}

Gastrointestinal symptoms were more common in the control group than in the children with CD (87\% vs $69 \%$ : $\mathrm{p}=0.007$ ). (Table 3). However, the presence of specific gastrointestinal symptoms or extraintestinal symptoms were similar in both groups ( $p>0.05$ for all). Abnormal 
examination findings were documented in only four patients: abdominal distension was noted in two children with $\mathrm{CD}$ and one control, whilst one child with $\mathrm{CD}$ was felt to have decreased muscle bulk.

Table 3. Symptoms in subjects with CD and Controls

\begin{tabular}{|l|c|c|c|}
\hline Symptoms & $\begin{array}{c}\text { Coeliac Disease } \\
(\mathbf{n = 7 0})\end{array}$ & $\begin{array}{c}\text { Controls } \\
(\mathbf{n = 9 0 )}\end{array}$ & $\begin{array}{c}\mathbf{p} \\
\text { value }\end{array}$ \\
\hline Gastrointestinal & $48(69 \%)$ & $78(87 \%)$ & 0.007 \\
\hline Vomiting & $6(9 \%)$ & $16(18 \%)$ & 0.11 \\
\hline Abdominal pain & $36(51 \%)$ & $54(60 \%)$ & 0.34 \\
\hline Restricted diet & $7(10 \%)$ & $3(3 \%)$ & 0.11 \\
\hline Decreased appetite & $7(10 \%)$ & $7(8 \%)$ & 0.78 \\
\hline Nausea & $6(9 \%)$ & $11(12 \%)$ & 0.61 \\
\hline Change in bowel habit & $25(36 \%)$ & $43(48 \%)$ & 0.15 \\
\hline Diarrhoea & $22(31 \%)$ & $31(34 \%)$ & 0.74 \\
\hline Constipation & $12(17 \%)$ & $16(18 \%)$ & 1.0 \\
\hline Growth concerns & $12(17 \%)$ & $16(18 \%)$ & 1.0 \\
\hline
\end{tabular}

\subsection{Family History}

Eighteen (26\%) children with CD were noted to have a family history of CD: in 12 cases this was documented as a first degree relative. Similarly, 20 (22\%) of the control group had a family history noted, with 9 documented as a first degree relative ( $p>0.05$ compared to $\mathrm{CD}$ group).

\subsection{Laboratory Data}

More children with CD had an anti-tTG $\operatorname{IgA}$ antibody result documented than in the control group (87\% vs 70\%; $\mathrm{p}=0.01$ ). (Table 4) Furthermore, more children with CD had a tTG result that was ten or more fold greater than the normal range $(67 \%$ vs $8 \%$; $p<0.001)$. The majority of children with CD with EMA testing were positive (95\% vs $19 \% ; \mathrm{p}=<0001)$. Only five of the CD group had a HLA DQ2/DQ8 measured, and all were positive.(Table 4).Twenty-eight (31\%) of the control group had an HLA DQ2/DQ8 performed: 19 were positive $(68 \%)$.

Table 4. Blood results in subjects with $C D$ and controls

\begin{tabular}{|c|c|c|c|}
\hline Blood tests & Coeliac disease & Controls & p value \\
\hline \multicolumn{4}{|l|}{ tTG Ig $A$ antibodies } \\
\hline Tested & $61(87 \%)$ & $63(70 \%)$ & 0.01 \\
\hline 5-49 units (positive) & $13(21 \%)$ & $17(27 \%)$ & 0.53 \\
\hline$>$ 50units & $41(67 \%)$ & $5(8 \%)$ & $<0.001$ \\
\hline \multicolumn{4}{|l|}{ Endomysial Antibodies } \\
\hline Tested & $41(59 \%)$ & $42(47 \%)$ & 0.15 \\
\hline Positive & $39(95 \%)$ & $8(19 \%)$ & $<0.0001$ \\
\hline \multicolumn{4}{|l|}{ HLA DQ2/DQ8 } \\
\hline Tested & $5(7 \%)$ & $28(31 \%)$ & 0.0002 \\
\hline Positive & $5(100 \%)$ & $19(68 \%)$ & 0.29 \\
\hline \multicolumn{4}{|l|}{ Full blood count } \\
\hline Tested & $43(61 \%)$ & $60(67 \%)$ & 0.51 \\
\hline Anaemia present & $2(5 \%)$ & $5(8 \%)$ & 0.70 \\
\hline \multicolumn{4}{|l|}{ Nutrient deficiency } \\
\hline Tested for & $43(61 \%)$ & $51(57 \%)$ & 0.63 \\
\hline Present & $17(40 \%)$ & $9(18 \%)$ & 0.02 \\
\hline Iron deficiency tested for & $41(59 \%)$ & $50(56 \%)$ & 0.75 \\
\hline Iron deficiency & $16(39 \%)$ & $5(10 \%)$ & $<0.002$ \\
\hline
\end{tabular}

The tTG 50 unit cut off (ten times the upper limit of the local normal range) gave a sensitivity of $67 \%\left(95^{\text {th }}\right.$ CI 54$79 \%)$, specificity of $92 \%\left(95^{\text {th }}\right.$ CI $\left.82-97 \%\right)$, a positive predictive value (PPV) of $89 \%\left(95^{\text {th }}\right.$ CI 76-96\%), and negative predictive value of $74 \%\left(95^{\text {th }}\right.$ CI $\left.76-96 \%\right)$. Adding the limited EMA and HLA data increased the specificity to $97 \%\left(95^{\text {th }}\right.$ CI $\left.89-99.5 \%\right)$, and PPV to $95 \%$ (95 ${ }^{\text {th }}$ CI 84-99\%).

Specific micronutrient deficiencies were tested for in $61 \%$ of subjects with $\mathrm{CD}$ and $57 \%$ of those without ( $p>0.05$ ).(Table 4). Iron levels were tested in $59 \%$ of those with $\mathrm{CD}$ and $56 \%$ of controls ( $\mathrm{p}>0.05$ ): iron deficiency was seen more commonly in the children with CD than in the control group (39\% vs $10 \%$; p <0.002).

\section{Discussion}

This limited retrospective application of the ESPGHAN diagnostic algorithm to symptomatic children in New Zealand, generated a moderately high specificity (97\%) and PPV (95\%). However, missing data points resulted in incomplete evaluation in this setting.

A number of prospective studies have recently evaluated the ESPGHAN guideline in different settings. A prospective study of 412 Italian adults and children with symptoms or signs consistent with $\mathrm{CD}$, found a positive EMA combined with a tTG $\operatorname{IgA} \geq 7$ times the ULN resulted in a specificity and PPV of $100 \%$ for diagnosis of $\mathrm{CD}$ (mucosal changes $\geq$ Marsh grade 2). [10] A prospective analysis of children undergoing investigation for $\mathrm{CD}$ in the Netherlands evaluated tTG IgA and EMA antibodies in 183 children.[11]All 87 of the patients with tTG >100 U/mL (10 times ULN) had CD on SBB; PPV and specificity $100 \%$, and sensitivity $73 \%$ (95\% CI 63-80\%).

Similarly, Sandström et al [12] prospectively screened 7161 children in Sweden with tTG IgA, EMA, and HLA DQ2/DQ8 and diagnosed 153 children with CD on SBB. tTG values of $\geq 10$ times ULN $(50 \mathrm{U} / \mathrm{mL})$ with positive EMA and HLA-DQ2 or DQ8 had a PPV and specificity of $100 \%$. A retrospective analysis of 150 children in Spain with tTG levels $\geq 10$ times ULN, positive EMA andHLADQ2 or DQ8 found a positive predictive value of $97 \%$ initially but this increased to $100 \%$ after the three patients with 'false positive' results had a gluten challenge and repeat SBB [13] The sensitivity of these tests in this cohort was $82 \%$. Despite the retrospective design of the current study, the specificity and PPV approach that seen in these prospective studies. This suggests that prospective analysis may confirm that the ESPGHAN diagnostic algorithm maybe applicable to the New Zealand paediatric population using local laboratory data.

It is important to avoid an incorrect diagnosis of CD, which would lead to unnecessary dietary restriction, extra family time and effort to prepare foods, and for some children potential growth impairment. Symptoms are likely to continue and the correct diagnosis may be missed. If this current study is representative of the local population, up to three children out of every hundred investigated for $\mathrm{CD}$ could be falsely diagnosed by adopting this guideline. The retrospective nature of this research resulted in only one child with $C D$ and 19 controls having all three laboratory studies performed. The majority of children also had all coeliac serology performed concurrently (rather than sequentially), potentially increasing the risk of false positives. The higher specificities and positive predictive values seen in 
recent prospective studies [11,12] highlight the importance of prospective analysis; ensuring the correct subjects enrolled into the correct groups, have the correct tests, at the correct times, to get the most accurate results from the ESPGHAN guidelines.

While the sensitivity of the ESPGHAN guideline in the current study was relatively low $(67 \%)$ it was comparable to the sensitivity of $73 \%$ seen in the Dutch study, [11] but lower than the $82 \%$ in the Spanish study. [13] Increasing sensitivity would risk compromising the high specificity obtained. The aim of the ESPGHAN guideline is to decrease the number of children requiring a SBB for diagnosis rather than eliminating it from the diagnostic pathway. If $67 \%$ of $\mathrm{CD}$ diagnoses could be made without a small bowel biopsy in Christchurch, this would be a large saving in duration of symptoms, anaesthetic and procedural risk, and cost to the health system.

Many studies have looked at the sensitivity and specificity of CD antibodies. In this study, the tTG IgA antibody ELISA used had a sensitivity of $89 \%(95 \%$ CI:81-94\%), and specificity of 65\% (95\% CI:55-74\%). EMA had a sensitivity of 95\% (95\% CI:89-98\%) and specificity of $81 \%$ (95\% CI:72-88\%). These sensitivities are lower than reported elsewhere. [14]This may reflect the relatively small number of children in our study, difference in laboratory testing kits, or accidental inclusion of children with other causes of intestinal inflammation due to retrospective collection of data. Some children with elevated tTG or EMA but normal SBB will subsequently develop CD [13,15]. Auricchio et al [16] followed a group of 175 asymptomatic children with elevated tTG for nine years; $43 \%$ continued to have elevated tTG, $20 \%$ became negative, and 37\% fluctuated between elevated and normal. Overall $67 \%$ still had normal SBB after nine years of follow up.

Very few subjects in the current study underwent HLA genotyping. This probably reflects the recent introduction of this test and its absence from the current diagnostic algorithm. Far more controls had their HLA genotype tested, showing its usefulness as a test of exclusion in children with mildly elevated or equivocal tTG.

The ratio of males to females (1:1.9) in our CD group was slightly lower than those reported in paediatric populations in other studies, 1:2.7 in Spain, [17] and 1:2.5 in Auckland, New Zealand. [18] However it was higher than the ratio of 1:1.4 found in a previous local study by Cook et al [4] that included a small sub-group of children under 19 years old.

There was no difference between ethnicities in the two groups, however Maori were under represented. Nine percent of the Christchurch population identify as Maori [19]. This contrasts with just $1.4 \%$ in the CD group and $4.4 \%$ in the control group of the current study. This is consistent with the higher prevalence of CD in European populations, [20] however it does not explain why Maori children are under-represented in the control group. This may be due to lower clinical suspicion in this ethnic group, less access to health care, or the sample size. Ethnicity data was supplied by parents and recorded in the hospital electronic database. This database will only allow one ethnicity to be recorded for each patient. Mixed heritage is becoming increasingly common, so this data source may be inaccurate.
This study showed a higher frequency of gastrointestinal symptoms in children without coeliac disease $(p=0.007)$. This may be due to a number of children with $\mathrm{CD}$ presenting with only extraintestinal symptoms. Previous studies have also failed to show increased gastrointestinal symptoms in those with CD. [21,22].

Multiple findings in our study suggest that the retrospective design limited the accuracy of data collection. Ten percent of children in both groups had limited documentation in their notes, some due to direct referral for SBB (high tTG levels) from local practitioners and peripheral centres. Fewer children in the control group had tTG measured and low numbers had all three assessments. Potential inaccuracies in identifying appropriate children for this study may have limited the ability to detect differences between the two groups, and decreased the apparent sensitivity of tTG measurement. The study included a moderate sample size, but this may have been inadequate to fully represent smaller population groups, or the smaller group of children with mainly extraintestinal CD symptoms.

\section{Conclusion}

Limited use of HLA DQ2/DQ8 testing limited the assessment of the ESPGHAN guidelines in the current population. However, the isolated use of the anti-tTG antibody cut off of 10 times the ULN, generated moderately high specificity of $92 \%$. A potential $67 \%$ reduction in the number of diagnostic biopsies performed would significantly reduce the work load and cost to the health system along with inconvenience and stress to families. This would likely increase patient satisfaction with the diagnostic process. The value of the 2012 ESPGHAN Guideline for the diagnosis of CD in New Zealand should now be evaluated prospectively.

\section{References}

[1] Fasano A, Catassi C, "Clincal Practice. Celiac Disease," N Engl J Med, 367(25), 2419-2426, Dec.2012.

[2] Husby S, Koletzko S, Korponay-Szabó et al, "European Society for Pediatric Gastroenterology, Hepatology, and Nutrition Guidelines for the Diagnosis of Coeliac Disease", JPediatr Gastroenterol Nutr, 54(1), 136-160, Jan.2012.

[3] Aziz I, Karajeh MA, Zilkha J, Tubman E, Fowles C, Sanders DS, "Change in awareness of gluten-related disorders among chefs and the general public in the UK: a 10-year follow-up study,'Eur J Gastroenterol Hepatol, 26(11), 1228-33, Nov.2014.

[4] Cook B, Oxner R, Chapman B, et al, "A thirty-year (1970-1999) study of coeliac disease in the Canterbury region of New Zealand," N Z Med J, 117(1189), Feb.2004.

[5] Tanpowpong P, Ingham TR, Lampshire PK et al, "Coeliac disease and gluten avoidance in New Zealand children," Arch Dis Child, 97(1), 12-16, Jan.2012.

[6] Marsh MN, "Gluten, major histocompatibility complex, and the small intestine. A molecular and immunobiologic approach to the spectrum of gluten sensitivity ('coeliac sprue')," Gastroenterology, 102(1), 330-54, Jan.1992.

[7] Graphpad Software. QuickCalcs. www.graphpad.com/quickcalcs/ (accessed January 2014)

[8] World Health Organisation. WHOanthro v 3.2 .2 calculator, January 2011 and macros.

http://www.who.int/childgrowth/software/en (accessed February 2013). 
[9] World Health Organisation. The WHO Child Growth Standards. http://www.who.int/childgrowth/standards/en/ (accessed February 2013).

[10] Alessio MG, Tonutti E, Brusca I et al,"Correlation between IgA tissue transglutaminase antibody ratio and histological finding in celiac disease,"J Pediatr Gastroenterol Nutr, 55(1), 44-9,Jul.2012.

[11] Mubarak A, Wolters VM, Gmelig-Meyling FHG et al, "Tissue transglutaminase levels above $100 \mathrm{U} / \mathrm{mL}$ and celiac disease: A prospective study," World J Gastroenterol, 18(32), 4399-4403, Aug.2012.

[12] Sandström O, Rosén A, Largerqvist C, et al, "Transglutaminase IgA antibodies in celiac disease mass screening and the role of HLA-DQ genotyping and endomysial antibodies in sequential testing," J Pediatr Gastroenterol Nutr, 57(4), 472-6, Oct.2013.

[13] Klapp G, Masip E, Bolonio M, et al, "Celiac disease: the new proposed ESPGHAN diagnostic criteria do work well in a selected population,” J Pediatr Gastroenterol Nutr, 56(3), 251-6, March.2013.

[14] Giersiepen K, Lelgemann M, Stuhldreher N et al, "Accuracy of Diagnostic Antibody Tests for Coeliac Disease in Children: Summary of an Evidence Report," JPediatr Gastroenterol Nutr, 54(2), 229-241, Feb.2012.

[15] Piccoli A, Capelli P, Castagnini A et al, "Latent celiac disease in subjects with serum anti-endomysial antibodies and normal intestinal biopsy," Pediatria Medica e Chirurgica, 24(5), 358-62, Sep-Oct.2002.

[16] Auricchio R, Tosco A, Piccolo E et al, "Potential celiac children: 9-year follow-up on a gluten-containing diet," Am J Gastroenterol, 109(6), 913-21, Jun.2014.

[17] Mariné, M, Farre C, Alsina M et al, "The prevalence of coeliac disease is significantly higher in children compared with adults," Aliment Pharmacol Therap, 33, 477-486, Feb.2011.

[18] Westerbeek E, Mouat S, Wesley A, Chin S, "Coeliac disease diagnosed at Starship Children's Hospital: 1999-2002,” NZ MedJ, 118, 35-43, Aug.2005.

[19] Christchurch City Council. Age and Ethnicity. http://www.ccc.govt.nz/cityleisure/statsfacts/census/agegenderethn icity.aspx (accessed January 2014).

[20] Gujral N, Freeman HJ, Thomson AB, "Celiac disease: Prevalence, diagnosis, pathogenesis and treatment," World J Gastroenterol, 18(42), 6036-6059, Nov.2012

[21] van der Windt DA, Jellema P, Mulder CJ, Kneepkens CM, van der Horst HE et al, "Diagnostic Testing for Celiac Disease Among Patients With Abdominal Symptoms A Systematic Review," JAMA, 303(17), 1738-1746, May.2010.

[22] Rosen A, Sandstrom O, Olof C et al, "Usefulness of symptoms to screen for coeliac disease," Pediatrics, 133(2), 211-8, Jan.2014. 